\title{
El uso de la lengua aborigen como práctica de evangelización: Domingo Milanesio y su prédica en mapuzungun (fines del siglo XIX y principios del siglo $\mathrm{XX}$ )
}

\author{
María Andrea Nicoletti \\ Universidad Nacional del Comahue, Argentina \\ manicoletti@jetband.com.ar \\ Marisa Malvestitti \\ Universidad Nacional de La Pampa, Argentina \\ malves@bariloche.com.ar
}

\begin{abstract}
Resumen
El proceso de evangelización católica se ha desarrollado en medio de una compleja situación de conquista y de violencia real y simbólica, con el fin de controlar, disciplinar e introducir una nueva cultura, por medio de la prédica de la doctrina y la comunicación de una fe; $y$, para este fin, la opción por el uso de la lengua dominante o la vernácula constituyó una cuestión central. Entre los misioneros más destacados del período de conquista de la Patagonia (1879-1884), encontramos al salesiano Domingo Milanesio, que utilizó el mapuzungun (lengua mapuche) en la prédica oral y en la publicación de materiales escritos. El análisis de su práctica no sólo nos permite analizar la relación entre los misioneros y los indígenas en el escenario posconquista, sino, además, el uso de esta lengua, su circulación en ese período y las cadenas intertextuales con las producciones de los misioneros precedentes (lazaristas y franciscanos), resignificadas posteriormente por los salesianos.
\end{abstract}

Palabras clave: evangelización, misioneros, Pampa, Domingo Milanesio, mapuzungun, mapuches.

\begin{abstract}
The process of catholic evangelization has been developed in a complex situation of conquest, in which real and symbolic violence held the purpose of controlling, disciplining and introducing a new culture, through the doctrine and the faith. And, in this process, the choice of using the dominant or vernacular
\end{abstract}




\section{FRONTERAS}

language constitutes a central issue. Among the most important missionaries of the period of conquest of the Patagonia (1879-1884), the salesian Domingo Milanesio was well-known by his use of mapuzungun, (mapuche language) as much in the oral evangelization as in the publication of written materials. The analysis of their practice allows us to analyze the relation between the missionaries and the natives in the post conquest scene, as well as the circulation and use of this language in that period and to establish the intertextual chains that can be established with the productions of the preceding missionaries (Lazarists and Franciscans), later resignified by the Salesians.

Key words: Evangelization, missionaries, Pampa, Domingo Milanesio, mapuzungun, mapuche.

\section{Antecedentes y fuentes de los catecismos en mapuzungun ${ }^{1}$}

En la historia de la evangelización de la Patagonia de fines del siglo XIX y principios del XX, el análisis de las prácticas de comunicación de la doctrina cristiana y la administración sacramental constituyeron un tema clave para comprender las relaciones entre indígenas y misioneros en el complejo contexto de la conquista, signado por la violencia, la distribución diferencial del espacio y la reorganización de las relaciones entre los distintos actores sociales. El conocimiento y dominio de la lengua de los sujetos de evangelización permitió crear y hacer circular discursos religiosos que buscaron homogeneizar y controlar al otro mediante categorías que rigen la relación entre lo humano y lo divino. La lengua jugó un papel preponderante para la transmisión y la imposición de la fe católica. El hito fundamental que abrió la posibilidad de catecismos en lenguas vernáculas para América fue el III Concilio Limense, que tradujo sus catecismos al quechua y aymara (Durán, El Catecismo). Esos catecismos (catecismo breve y catecismo mayor) continuaron utilizándose hasta el Concilio Plenario Latinoamericano de 1899, con el mismo objetivo de unificación de la diversidad doctrinal y de contenido de los catecismos o cartillas circulantes en lenguas vernáculas mediante una metodología de preguntas y respuestas para facilitar el ejercicio memorístico ${ }^{2}$. El Concilio de 1899 también insistió en el "aprendizaje de las lenguas indígenas" por parte de los sacerdotes y religiosos (Obispos, tít. XI, cap. III, decs. 772 y 774 y cap. IV, dec. 773).

1 Se han presentado avances parciales de este tema en el II Congreso Internacional de LaS LenguaS, Buenos Aires, en julio de 2007, y las XI Jornadas Interescuelas de Departamentos de Historia, Tucumán, en septiembre de 2007.

2 Recomienda uniformidad en la conversión y educación cristiana de los indígenas. 
La utilización de la lengua vernácula en la situación sobre la que indagamos - los usos del mapuzungun (de mapu "tierra", y zungu "habla") en las prácticas de evangelización salesiana en la Pampa y la Norpatagonia - es, en líneas generales, similar a la de otras áreas americanas con población indígena. Los primeros catecismos en mapuzungun fueron producidos por la orden jesuita. Entre los textos de mayor circulación se destacaron los publicados por Valdivia, Febrés y Havestadt, que constituyeron fuentes innegables para las publicaciones posteriores del mismo tipo.

Por su parte, los antecesores de la Congregación Salesiana en la evangelización pampeano- patagónica, los misioneros lazaristas ${ }^{3}$ confeccionaron los tres catecismos más difundidos en la época: Doctrinale elementare y Doctrinale familiare (1875), del padre francés José María Salvaire (1847-1899) ${ }^{4}$, el Pequeño Manual del Misionero para evangelizar a los indios fronterizos (1876), del padre italiano Pablo Emiliano Savino (1839-1915) y el Pequeño catecismo castellano-indio para enseñar la doctrina cristiana a los indios que están en casa de particulares $(1879)^{6}$ del padre José Pablo Birot ${ }^{7}$. Tanto Salvaire como Savino y Birot contaron con el auxilio indudable del texto de Febrés ${ }^{8}$.

3 Los Lazaristas, José María Salvaire, Fernando Meister y Pablo Savino establecieron sus misiones entre 1873 y 1879 en el ámbito de la actual provincia de Buenos Aires (Hux 247-316).

4 El catecismo consta de cuatro instrucciones: "Primera Instrucción: Motivos que tenemos para hacernos cristianos"; "Segunda Instrucción: Dios”; "Tercera Instrucción: Creación del Hombre" y "Cuarta Instrucción: El pecado original. La Santísima Trinidad y la Encarnación. Vida y muerte de Nuestro Señor Jesucristo" (Durán, En los Toldos 562).

5 Texto bilingüe a dos columnas en forma de interrogatorio que contiene: "Catecismo menor", "Confesionario Indio", "Repertorio de frases usuales y exhortación", "Direcciones necesarias sobre la escritura, pronunciación y acentuación del idioma indio"; "Del acento" (Savino).

6 Es un texto bilingüe a dos columnas a modo de interrogatorio que contiene grupos de preguntas sobre el dogma (Birot). Este texto también fue conocido por Barbará y Durán (Durán, "Catecismos" 48).

7 Los dos últimos fueron publicados y reeditados, en tanto que el texto de Salvaire permaneció inédito hasta 2002, cuando fue publicado en edición facsimilar en Durán (En los Toldos).

8 Hay constancia de que se encontraba en la biblioteca del primero. En cuanto a Savino, indica entre las fuentes que utilizó para su catecismo, "una vieja gramática sobre la lengua de los indios de Chile", facilitada por su lenguaraz, José Carranza Calfuiñ (Durán, "Catecismos" 50, 54, 62). La circulación del texto de Febrés también se evidencia en la crítica de la publicación de Savino efectuada por el coronel Barbará: "prescindimos de citar el Manual del misionero, publicado en esta ciudad en 1877 por un sacerdote que ha ocultado su nombre tras el seudónimo de 'un siervo de María Santísima' porque ese manual es una copia del Arte de la lengua chilena, escrito por Andrés Febres, misionero de la Compañía de Jesús, e impreso y publicado en Lima en 1765" (14). Según Vignati, la acusación de Barbará es una mentira deliberada para ocultar su propia copia del texto de Febrés (Durán, "Catecismos" 49). 


\section{FRONTERAS}

En los tres casos se trata de reelaboraciones libres a partir de este texto, lo que se advierte en la opción por construcciones gramaticales diferentes de las del original, en la selección léxica de algunos términos y en la transcripción fonética en mapudungun, que deliberadamente reproduce las variantes usuales en el área pampeana.

Los padres Marcos Donati y Moisés Álvarez, de la orden franciscana, a cargo del Colegio de Propaganda Fide en Río IV (actual provincia de Córdoba), y en contacto con los grupos originarios ranqueles de la zona mediterránea y pampa central, también acudieron al texto de Febrés (Durán, "Catecismos" 59-61) $)^{9}$. De este modo puede observarse un circuito de difusión de este tipo de materiales, para el que la cordillera no operó como un obstáculo, así como también pueden reconocerse claras relaciones intertextuales establecidas entre las producciones de quienes llevaron adelante su práctica misional en el ámbito territorial mapuche entre el siglo XVII y fines del siglo XIX.

Al iniciar los salesianos su tarea pastoral en la Patagonia en 1880, partieron de los instrumentos catequísticos producidos previamente. Si bien en el área otras lenguas indígenas se encontraban vigentes — gününa iajüch o "pampa", y tehuelche-, la lengua mapuche o mapuzungun era la que contaba con el mayor número de hablantes $\mathrm{y}$, además, funcionaba como lengua franca, en tanto que el español, lengua de los blancos, recién se estaba difundiendo entre los indígenas mediante los procesos de incorporación forzada al ejército o de escolarización y reparto de los niños. Un misionero salesiano italiano, Domingo Milanesio, se aplicó rápidamente a la tarea de aprenderla para poder llevar adelante su labor. El análisis de su obra publicada ${ }^{10}$ nos permite hablar de las siguientes fuentes: Febrés, Savino —obra que, además, la congregación reimprimió en 1900, en la Tipografía del Colegio Pío IX, con un apéndice escrito por él一, las publicaciones del capuchino Félix José de Augusta, quien desempeñó tareas pastorales en la Araucanía desde $1895^{11}$ y el Manual de pie-

9 Pérez Zavala (26-27) cita otra carta en la que el padre Moisés Álvarez solicita que el gobernador de Mendoza envíe las dos copias de la gramática de Febrés, y no una sola, como había hecho, y también, si era posible, la obra de Barbará.

10 Un análisis crítico de su obra publicada se encuentra en: Malvestitti y Nicoletti ("Padre").

11 En la tercera parte de la Etimología araucana se reproducen en edición bilingüe españolmapuzungun 108 oraciones tomadas del repertorio de frases usuales del Pequeño Manual de Savino. También se incluyen las versiones al español de los cuentos "El caballo blanco" y "El zorro aprende a cantar" y ocho canciones (ülkantun) tomadas de las Lecturas Araucanas de Augusta. Varios de los textos están intervenidos por Milanesio, ya sea para agregar alguna expresión ausente en la versión al español, introducir notas al pie, incluir o cambiar 
dad. El contacto con estos últimos materiales de origen trasandino, que le eran contemporáneos, seguramente se produjo en algunos de los numerosos viajes que hizo Milanesio a Chile entre 1884 y 1914 (Garófoli, Breve) $^{12}$.

En pocos años, mediante la política aculturadora propugnada por el Gobierno Nacional, y también por la Congregación Salesiana, se fue diluyendo la funcionalidad de la lengua indígena como medio de intervención misionera, y fue reemplazada por el español ${ }^{13}$, en un contexto en el que la "Educación universal, uniformización lingüística, unificación de la memoria histórica, expansión de las prácticas asociativas y consolidación del sistema eleccionario fueron cinco de las vías fundamentales - que no únicas- para la construcción de la homogeneidad" (Quijada 30-31).

\section{Patiru (padre): la práctica lingüística en mapuzungun de Domingo Milanesio}

Domingo Milanesio arribó a Viedma hacia fines de 1880, y en 1883 comenzó los circuitos de misiones volantes que le permitieron un contacto fluido con los grupos indígenas desmembrados por las campañas militares ${ }^{14}$. Participó

el título del texto en el caso de las canciones, y efectuar algunas modificaciones gramaticales en el texto de Savino. De ellas, destacamos el agregado de la frase correspondiente a un emisor de sexo femenino en la proposición relativa al estado civil, la inserción de mu tras la forma verbal no finita en -lu (ca thipantu cúpalu mu, 'en año pasado') y la modificación de la referencia a la interacción entre una segunda persona Agente y una primera persona Paciente (pepi núthamcúnuymi rúpú amulu Junin ‘¿Puede Ud. enseñarme el camino de Junín?', en vez de núthamcúnuen como aparece en Savino), la que es coherente con la expresión de la referencia pronominal según Milanesio (La Patagonia 18).

12 También, en una carta al Rector Mayor de los Salesianos, Milanesio le manifiesta que "tendría también el material para hacer reimprimir un pequeño diccionario sobre la misma lengua. No es trabajo mío, pero la mayor parte compilado de otros misioneros de Chile. Yo no tuve otra cosa que hacer que juntar algunos términos que no estaban para completarlos" ("Carta de Milanesio"). En italiano, la traducción es de María Andrea Nicoletti.

13 Solamente podemos citar a un contemporáneo a Milanesio en la Patagonia Norte con conocimientos de la lengua: el padre Zacarías Genghini (BS 8 de 1904). Esta práctica ha sido retomada a mediados del siglo XX por los misioneros salesianos Oscar Barreto y Francisco Calendino.

14 Nació en Settimo Torinese, cerca de Turín (Italia), el 3 de agosto de 1843 y falleció en Bernal, Buenos Aires, el 19 de noviembre de 1922. A los veintitrés años de edad entró a la Sociedad Salesiana, y pasados los treinta años fue ordenado sacerdote. Milanesio se formó con Don Bosco y participó íntimamente en la etapa inicial de la Pía Sociedad. Esto fue tan determinante como su formación como misionero por el vicario apostólico Juan Cagliero. Llegó a la Argentina en la tercera expedición misionera, a cargo de Giacomo Costamagna, en 1877. Su primer destino fue en la Parroquia San Juan Evangelista, en La Boca, y en 


\section{FRONTERAS}

activamente junto al vicario salesiano Juan Cagliero en la confección de los primeros circuitos misionales sobre el río Colorado y sobre el río Negro, la ciudad de General Roca, en el Alto Valle, y las misiones triangulares del Neuquén entre Confluencia, Junín y Chos Malal. Estos trayectos se articulaban con el espacio trasandino, e integraban las ciudades de Los Ángeles, Chillán, San Carlos y Concepción. Un mínimo reporte de su recorrido, publicado en los Bollettini Salesiani, permite señalar que en 1885 Milanesio tuvo contacto con los caciques Namuncura, Payleman, Ñancucheo y Sayhueque. Entre esta misión y el año 1893 Milanesio recorrió el Neuquén hacia Chos Malal y Río Negro, desde el Colorado y el Negro hasta Comallo y Valcheta, y en territorio chubutense visitó Rawson y contactó al cacique Sacamata. La fundación de Junín de los Andes en 1892 ligó el circuito neuquino con el sector cordillerano de Río Negro y Chubut. Allí Milanesio tenía contacto con las tribus de Painefilu y Pilquiman. Partiendo de ese centro, recorrió desde el norte neuquino hasta Chubut por la cordillera: Malbarco (actual Varvarco), Las Lajas, Trocoman, San Martín — donde predicó a los Curruhuinca-, Collón Cura y San Ignacio —donde volvió a ver a los Namuncura-, hasta el Nahuel Huapi, Bariloche, El Bolsón en 1907 y el río Manso en 1911.

\section{Mapa 1: Patagonia Norte. Poblaciones donde misionó Milanesio}

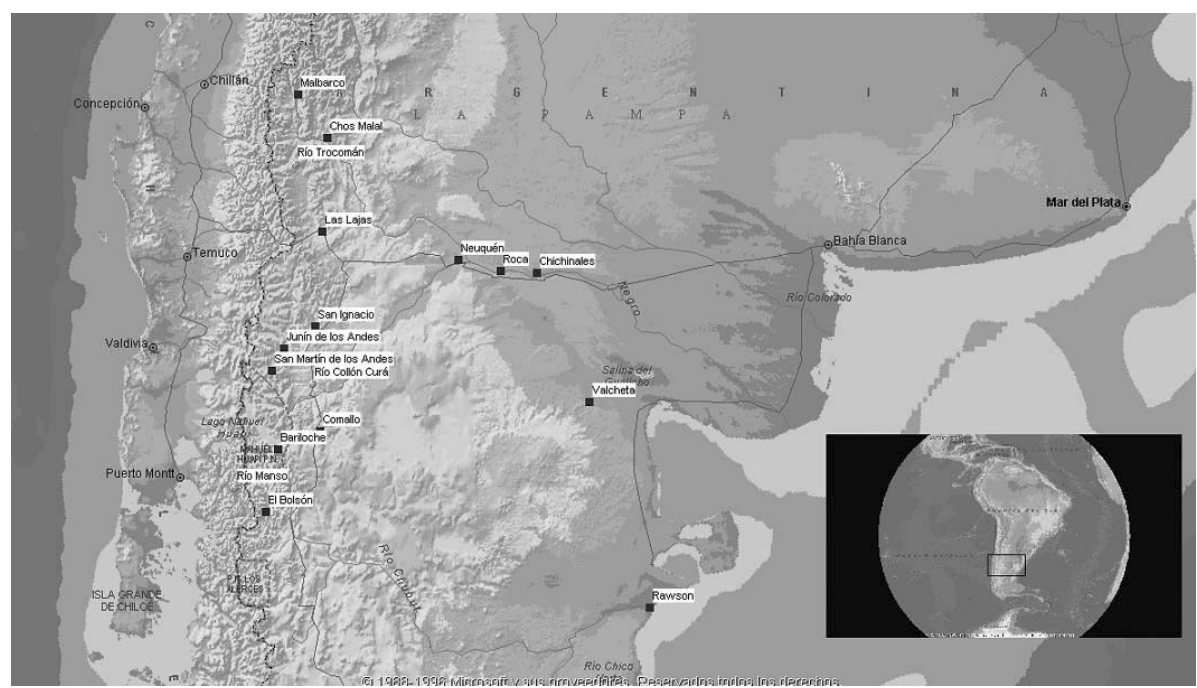

Fuente: Elaboración de las autoras.

1880 fue uno de los primeros misioneros destinados a la Patagonia. Hacia 1883 Milanesio comenzó las misiones volantes, que no abandonó hasta 1912. En su retiro en Bernal, en las afueras de Buenos Aires, levantó en la huerta una ruka, o casa mapuche, como símbolo de su vida misionera entre los indígenas de la Patagonia. 


\section{Fotografía 1. Encuentro con miembros de la tribu de Sayhueque, Carmen de Patagones, 1886}

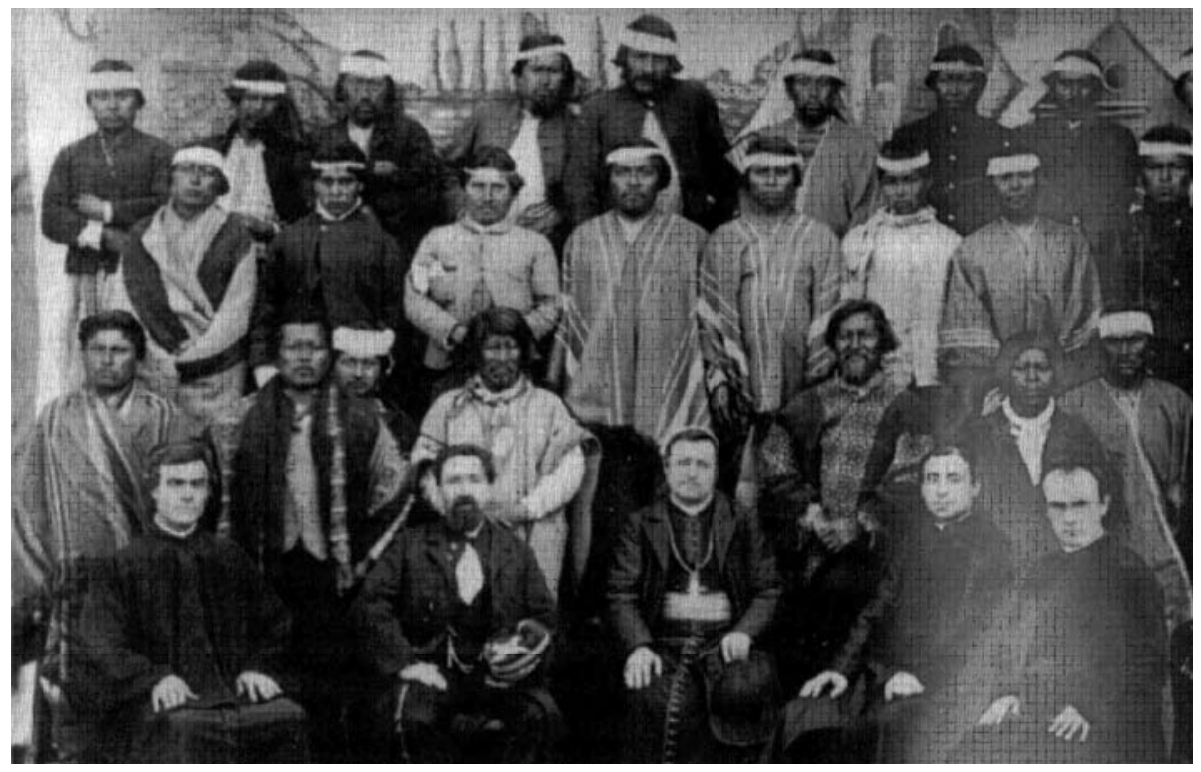

Sentados de izquierda a derecha: Domingo Milanesio, Lino O. de Roa, Monseñor Juan Cagliero, Antonio Riccardi y Tadeo Remotti.

Fuente: Catálogo Ecos históricos de la Patagonia. Aborígenes y misioneros, siglo XIX (42).

Cuando los circuitos de misión volante de los salesianos se pusieron en marcha, Domingo Milanesio se preocupó por definir dos cuestiones fundamentales para implementar una prédica eficaz de la doctrina e iniciar así la "conversión de infieles": recopilar, escribir y difundir catecismos y gramáticas mapuches y puntualizar, mediante un manual misionero regional, la formación y las técnicas de evangelización para la misión en Patagonia (Nicoletti, "Bases").

En este trabajo nos ocupamos de la primera cuestión, poniendo en foco su uso de la lengua vernácula como herramienta metodológica de su práctica evangelizadora, en la oralidad y en la escritura. En cada uno de estos formatos pueden reconocerse motivaciones o fines distintos: uno comunicativo, dado en la oralidad, con el objetivo de acercarse de los indígenas para catequizarlos; y otro, propagandístico y argumentativo, dado en sus publicaciones destinadas a la sociedad europea. En este último caso es posible reconocer las fuentes escritas a las que ha acudido, ya sea porque las explicita él mismo o porque las reconocemos mediante análisis contrastivo; 


\section{FRONTERAS}

en cambio, si bien hay indicios de una tarea de adecuación dialectal en los materiales que publicó, en los textos no precisa quiénes fueron los indígenas que lo auxiliaron en esa tarea ${ }^{15}$.

\section{La evangelización oral}

La práctica evangelizadora de las misiones rurales tenía una dinámica precisa que Milanesio describe en sus notas (BS 12 de 1886; 9 de 1899). Los misioneros tuvieron especial cuidado, antes de bautizar a los indígenas adultos, de "instruirlos en torno a las verdades principales de la fe y los medios para salvarse, si fuera posible también el precepto" ( $B S 9$ de 1899; 7 de 1884), siguiendo la "práctica de los jesuitas del siglo pasado en la Araucanía" (BS 9 de 1899). Se enseñaban los contenidos básicos de la doctrina: los misterios de la Unidad, la Trinidad y la Redención, el Bautismo como medio de salvación, que practicaran el bien y se abstuvieran del mal, de acuerdo con el Decálogo:

Y basta. Esto fue hasta ahora lo enseñado a los Indios de la Patagonia, no pudiéndoles enseñar más que eso, siéndonos imposible a nosotros extendernos por la dificultad de la lengua y por el poco tiempo que permanecemos, porque nos toca recorrer grandes distancias. (BS 7 de 1884).

La dinámica de aprendizaje era la clásica repetición de memoria. Se comenzaba con la señal de la cruz por imitación gestual y repetición $(B S 7 \text { de 1881 })^{16}$, y posteriormente se enseñaban las oraciones católicas y jaculatorias "en su idioma indio", durante media hora o una hora, según las circunstancias ( $B S$ 11 de 1885; 9 de 1899), y ante las dudas, volvía a hacerles repetir las frases y utilizaba el mapuzungun como herramienta, "para asegurarme que todos lo hubiesen entendido". La misma metodología se aplicaba a los niños. Refiriéndose a una situación concreta de catequización, señala Milanesio que "todos lograron aprender cinco páginas de doctrina, el Padre Nuestro, el Ave y el Credo y todo lo aprenden en su idioma", actuando en ese caso algunos

15 Sólo una vez menciona la ayuda de un intérprete llamado Pailalauquen, en Junín en 1913 (BS 9 de 1913). Ignoramos quiénes proveyeron las versiones al mapuzungun de las emisiones propuestas por el Comité Turinense en 1898, aunque es sabido que aquellos misioneros estaban usualmente acompañados por indígenas que dominaban ambas lenguas, ya que era una práctica usual desde la época colonial llevar indígenas "evangelizados y civilizados" a Europa, como muestra de la obra realizada. Algunas de estas visitas han sido publicadas (BS 9 de 1892).

16 La gestualización de la señal de la cruz se describe también en Savino (25). 
niños indígenas como improvisados catequistas para los demás, y adoptando Milanesio el rol de examinador para comprobar que los conocimientos se recordaran (BS 7 de 1884).

Tres ejemplos provistos en los textos muestran el uso de la lengua en tales situaciones. En las dos primeras observamos cómo en la catequesis previa para la administración del bautismo se practicaba el interrogatorio doctrinal en mapuzungun:

1)

- Iney cam pigeymi? (¿Cómo te llamas?).

- Respuesta : Cajetano-Luis pigen. (Me llamo Cayetano-Luis).

- Chem ca ta ayieymi Dios tañi Iglesia meu? (¿Qué quieres de la Iglesia de Dios?).

- Mupiltuhue ayúfin (Quiero la fe).

- Chem ca ta elueymi mupiltuhue? (¿Qué te da la fe?) [¿Qué das a la fe?].

- Cúme que mogen chumúl no rume afnole eluen (Me da la vida feliz y eterna) [Me das buenas vidas (que) nunca terminen].

- Cúpa cúchaloncogeymi? ${ }^{17}$ (¿Quieres ser bautizado?) [¿que te sea lavada la cabeza?].

- May, Padre, cúpa cúchaloncogen (Sí, Padre, quiero el Bautismo). (BS 11 de $1885)^{18}$

Salvo aquellas palabras que no estaban permitido traducir, para evitar equivalentes que se prestaran a la confusión (Dios e Iglesia, por ejemplo), las traducciones del mapuzungun y el italiano varían en función de la explicación del precepto que quiere darse a entender, intentando proporcionar un sentido más cercano a la cultura a la que se predica la doctrina. Así, la palabra "feliz"

17 cúchalo mogeymi en el original, por error de impresión.

18 Tradujimos las frases del italiano al español entre paréntesis (María Andrea Nicoletti) y del mapuzungun al castellano (Marisa Malvestitti) entre corchetes, para observar la variación de términos o las adaptaciones que hace el misionero. Estas últimas figuran en bastardilla y entre corchetes. 


\section{FRONTERAS}

se reemplaza por "buena", "eterna", o por "que nunca termine", y la traducción de "bautizado", que cambia completamente al mapuzungun enfocando el sentido en el rito externo, y entre ellos seleccionando sólo el signo del agua. La práctica de lavarse el cuerpo, o la cara y la cabeza, se daba en el wiñoy tripantü, rito ancestral de la renovación de las fuerzas del cosmos y la naturaleza en el solsticio de invierno, y podemos inferir que los misioneros tomaron una práctica cultural y la reelaboraron como bautismo.

Según Foerster, de los sacramentos católicos el bautismo es el más requerido por "su simbólica purificadora" del perimontun (comunicación o señal sobrenatural manifestada en forma de sueño o visión), causado "por el contacto con el espíritu malo, que perturba profundamente a la persona. [...] La manera de exorcisar el perimontun es través de la señal de la cruz. Los perimontun habrían disminuido por efecto del ritual bautismal" (111).

El segundo texto, que por su extensión no reproducimos completo, tiene el formato de Plática. El misionero se dirige a un cacique, un longko, un equivalente a un jefe poderoso, a quien va a bautizar. Su mismo nombre, que significa "cacique o cabeza de oro", parece simbólico. El misionero requiere que este longko haga su profesión de fe en las tres personas de la Trinidad y que luego haga el acto de contrición, después de lo cual será bautizado él y, a continuación, toda su gente. En este caso, las diferencias de traducción no son en función del mapudungun, sino del italiano, ya que el texto estaba dirigido a mostrar a los cooperadores salesianos el momento en que el misionero bautizaba al "cacique de la tribu". El misionero vuelve a centrarse en el rito bautismal externo, pero agrega "SANTO" (con mayúsculas), para dejar claro que se refiere a un sacramento sagrado cuyo poder reside en las "arcanas palabras"19.

\section{2)}

-Allkcútulege, Loncomilla, petu ga tami cúchalonconoal, tami ga pu che cúchalonconoal cay, inche petu cume nemul pinoael cay, eymi tami che cay unequechi may fei pilemn. (Atento, Loncomilla, antes que yo vierta el agua sobre tu cabeza o pronuncie la formula de las arcanas palabras del Santo Bautismo, es necesario que tu y tus súbditos (dependientes) acompañantes, hagan uno después del otro la profesión de fe). [Escucha atento, Loncomilla, antes de que seas bautizado y que tu gente sea bautizada también, y antes de que yo (no) diga la buena palabra, tú y también tu gente primero digan pues esto] [...]

19 Tradujimos las frases del italiano al español entre paréntesis (María Andrea Nicoletti) y del mapuzungun al español entre corchetes (Marisa Malvestitti), para observar la variación de términos o las adaptaciones que hace el misionero. Estas últimas figuran en bastardilla y entre corchetes. 
- Feley ga, feula lucutumun com femimn cay acto de contrición fey tairmn cay: (Bien, ahora arrodillaos todos y haced el acto de contrición diciendo así [ustedes también])

- Ah Dios ema- Chao ema inche ñi femfoe, montulfoe cay furenieen Dios ema, furenieen Chao ema, Inche fill zungu mu ayueymi, inche huerilcalielu aldun azquezuamquen fil tañi piuque meu, huerilcahuelayan inhche ñi huerilcan mu, huerilcahuelayan, - zoy ayiaeymi fil zungu meu. (Oh Dios mío, o Padre mío, creador y Redentor mío, ten piedad de mí [favoréceme oh Dios, favoréceme oh Padre]. Yo te amo sobre todas las cosas y me arrepiento de todo corazón, porque te he ofendido con mis pecados. Pero ahora sinceramente arrepentido, te prometo no ofenderte más y amarte sobre todas las cosas) [si yo pequé contra ti, me arrepiento mucho con todo mi corazón, ya no voy a pecar con mi pecado, ya no voy a pecar, te voy a amar más, por sobre todas las cosas]

- Fele, fele, muchaula femimn gunrel santa Cruz: Chao, Fothum cay, Spiritu Sancto kay ta ñi gúey meu felepe. (Bien, ahora levantaos y haced el signo de la Santa Cruz. In nomine Patris et Filii et Spiritu Sancti. Amen.”) [Bien, bien, ahora hagan la señal de la Santa Cruz: en el nombre del Padre, del Hijo y del Espíritu Santo, Amén $]^{20}$.

En el último ejemplo se presenta un diálogo que Milanesio mantiene con una indígena llamada Annuy-car, a quien había bautizado diez años antes en la misión en Valcheta. Cuando ella le recuerda este hecho al misionero, este le hace repetir mediante el interrogatorio las principales verdades del credo en mapuzungun (BS 1 de 1912). El diálogo se centra finalmente en la muerte, el infierno y el Paraíso, apelando a las emociones: Annuy-car arruga la frente, tiembla, teme. Queda claro que las almas buenas ganan el Cielo y las malas, el infierno. También enfatiza que la vida está sólo en manos de Dios, quien la concede y la quita y despoja a la muerte de todo sentido sacrificial, de la fuerza antagónica del wekufü ${ }^{21}$.

3) - (¿Bien! Respóndeme un poco: ¿Hay Dios?) - Dios mley [Hay Dios]

20 Este texto aparece en Milanesio, Raccolta (xvi), cuyos destinatarios son los cooperadores salesianos (seglares de la familia salesiana) de España, Italia y el litoral austriaco, y es ilustrado por una imagen alusiva. Un análisis detallado del mismo se encuentra en Nicoletti ("Una puesta").

21 Para los mapuche la vida era infinita y las personas pasaban por diferentes estados a lo largo de su existencial; la muerte era uno de ellos, un tránsito hacia un lugar donde el alma viviría eternamente en el Wenu Mapu, con sus seres queridos. 


\section{FRONTERAS}

de la fistoria

Vol.13-1 / 2008

- (¿Y cuantas personas hay en Dios?) - Cla che mley [Hay tres]

- ¡Bien! ¿Sabes cómo se llaman?

- Chao, Fothúm, Espiritu Santo, cay (Se llaman: Padre, Hijo y Espíritu Santo) ${ }^{22}$

$-(¿ \mathrm{Y}$ estas tres personas son tres dioses?)

- Mu Padre, quiñe muthen (No, Padre, hay un solo Dios). [No, Padre, uno solo]

(Mostrándole entonces un Crucifijo le pregunté: - ¿Qué imagen es ésta?)

- Dios tañi Fothúm! (representa al hijo de Dios). [el Hijo de Dios!]

- (Jesucristo es Dios?)

- May, Padre [Sí, Padre].

- (¿Dónde murió?)

- Lay huente cruz meu! (Murió en la Cruz). [Murió sobre la cruz]

- (¿Por qué murió?)

- Inchiñ meu tain monstuam cúthal massa meu, tain puam huena meu (Murió para salvarnos, para liberarnos del infierno y ganar el cielo) [Murió para que nos libremos de la tierra del fuego, para que vayamos al cielo]

- (¿Tienes alma?)

- May, miepin (Sí, Padre, tengo un alma) [Sí, creo (mupin)/Sí, eso digo (eipin)]

- ¿Tu alma morirá?

- Muca, Padre, lalay inche ñi púllú (No, Padre, mi alma no morirá jamás) [no muere mi alma]

- (¿Y dónde irá tu alma después de la muerte, si es buena?)

Alzando los ojos con una profunda expresión de fe:

22 “Se llaman" no aparece en la versión en mapuzungun. 
- Amuay hueny mu! [Irá al cielo].

- (¿Y si es mala?)

(Arrugando la frente y casi temblando, respondió con miedo):

- Amuay cúthal mapu mu! [Irá al infierno]

- (¿Y tu dónde quieres ir después de la muerte?)

(Y ella con un arrebato lleno de afecto):

- Inche cupa amuan hueme mu [Yo quiero ir al cielo].

- (¿Tu cuerpo resucitará al final del mundo?)

- Calùl uñomogetuary [...] (Sí, Padre, mi cuerpo saldrá del sepulcro para volver a vivir con el alma) [Calùl uñomogetuay- mi cuerpo volverá a vivir/resucitará]

- (¿Cuando tiempo estarán los buenos en el Paraíso y los malos en el Infierno?)

(Annuy-car, casi sin darme tiempo de terminar la pregunta, me respondió):

- Afnoché chipantu meu! (para siempre!) [hasta el año que no concluye]

- (¿Y quién manda la muerte a los hombres?)

- Dios múthen! (Solamente Dios y ningún otro) [Solo Dios/Dios nomás]

- (Bien, bien, terminemos; que el Señor te bendiga y te conceda a ti una muerte santa y el Paraíso).

Las expresiones que aparecen en estos textos fueron básicamente tomadas de los catecismos fuente que Milanesio consultó, y remiten a la repetición de un Credo sintético que precede al acto del Bautismo y asegura la comprensión del acto de $\mathrm{fe}^{23}$. Se trata de expresiones rituales, formulaicas o de estructura estable y vocabulario limitado, cuyo uso no necesariamente implicaba un manejo competente de la lengua. En los tres casos se resalta el deseo de los

23 Pueden identificarse expresiones tomadas de la alocución sobre el bautismo, el Credo y el catecismo que aparecen en Febrés (240-243; 184-185; 196-206), así como de los catecismos de Birot, de Savino, del Manual de piedad y del que él mismo publicaría. 


\section{FRONTERAS}

indígenas de aceptar la fe y se enfatizan las expresiones emotivas. Como vimos, los interlocutores que proponen los últimos textos son también emblemáticos: el longko Loncomilla, una persona de poder que es bautizada, y Annuy-car, que simboliza la conversión sostenida en el tiempo, desiderata de los misioneros. Mediante una operación de ficcionalización sobre situaciones vividas, Milanesio focaliza los notables resultados de la práctica misionera salesiana y provee argumentos para que la continuidad de su obra sea apoyada por los cooperadores de la misma.

\section{Catecismos y gramáticas en mapuzungun}

Las obras que sobre el tema compuso Milanesio fueron publicadas entre 1898 y 1917 , en el contexto de la última etapa de su actividad pastoral ${ }^{24}$. Nos centraremos aquí, específicamente, en la exposición de las relaciones intertextuales que se establecen entre estas publicaciones y los instrumentos de evangelización que hemos ido mencionando.

Como hemos visto, dada la necesidad de aprender la lengua por parte de los misioneros, a los catecismos propiamente dichos agregaban pequeñas gramáticas y diccionarios que les facilitaran tal adquisición. Milanesio no fue una excepción, y en dos de sus trabajos se dedicó a estas cuestiones, con resultados dispares. Abordó cuestiones léxicas en Etimología araucana, que en su correspondencia describe como "un pequeño diccionario", pero reconoce que "no es trabajo mío, sino la mayor parte compilado de otros misioneros de Chile. Yo no tuve otra cosa que hacer que juntar algunos términos que no estaban para completarlos" ("Carta de Milanesio"); en él Febrés es mencionado varias veces como fuente. Además de topónimos, las 691 entradas léxicas ${ }^{25}$ incluyen lexemas comunes, antropónimos e incluso palabras de origen no mapuche (quechua, español, tehuelche septentrional), y, como señalan investigaciones previas, el texto es de valor sumamente dudoso, ya que presenta numerosas etimologías erróneas o disparatadas ${ }^{26}$.

24 Hemos desarrollado este tema en Malvestitti y Nicoletti ("Evangelizar"; "Padre").

25 Que en varios casos aparecen reiteradas bajo grafías diferentes (Collico, Colico; Naico, Nauco) o idénticas (Antu-co, Antu-co; Cochi-có, Cochi-có).

26 Además de las críticas que pueden leerse, por ejemplo, en la introducción de Imbelloni (Perón xii-xiii), hay una referencia inédita de Juan Benigar, quien leyó la edición de 1918 y apuntó en 1926: "me ha defraudado malamente [...] es una mezcla de nombres de personas, de topónimos y de vocablos sueltos sin documentación alguna [...] Hay aquí vocablos araucanos, pero también quichuas, ingleses, franceses y otros que se tratan como araucanos. [...] Una crítica de este adefesio sería tiempo perdido [...] Milanesio inventa vocablos, les da vueltas tripas para 
Anteriormente, en La Patagonia, lingua, industria, costumi e religione dei Patagoni (1898), además de un breve catecismo y las oraciones católicas más usuales, había presentado "una pequeña gramática indígena que podría servir para el estudio del araucano" ("Carta de Milanesio") ${ }^{27}$ que sigue las descripciones gramaticales "clásicas" de la lengua, y aborda la fonología y la acentuación, el sustantivo, el verbo en sus diferentes tiempos y modos, las "transiciones" y la estructura de las proposiciones subordinadas. La primera parte está tomada del Pequeño manual, a cuyo texto Milanesio hizo algunas modificaciones y abreviaciones. Las demás secciones, relativas a las categorías nominales y verbales, son sintéticas, y en los ejemplos seleccionados se aparta de las gramáticas jesuitas en las que se basó. También en esta obra registra un listado de 64 sustantivos en araucano, pampa y tehuelche, que se reiteraría en publicaciones subsiguientes - en las cuales señala que fueron recopilados por él mismo "en las excursiones entre los indios"-, los numerales de uno a mil en esas lenguas y 143 frases en mapuzungun, organizadas en 18 apartados, según los elementos gramaticales que se pretende elucidar en cada caso. Estas frases, sencillas y apropiadas para la interacción cotidiana, versionan las frases que en italiano habían sido "propuestas a los Misioneros salesianos de la Patagonia por el Ilustre Comité Católico y Científico de la Exposición de Turín, para traducir al araucano el año 1898" (Milanesio, La Patagonia 26) ${ }^{28}$.

afuera y les cambia el significado según como le parece conveniente. Su vocabulario araucano es pobrísimo y no alcanza el número de "dos mil y tantos términos" ni mucho menos. De la gramática araucana no sabe ni el principio del principio" (Legado Juan Benigar). Los errores de Milanesio se deberían en gran medida a su desconocimiento de los procedimientos morfológicos de la lengua, aunque no hay que descartar la inclusión de toponimias populares que haya recopilado en terreno, ya que en estas suelen aparecer interpretaciones semánticas erróneas de los constituyentes o de la unidad léxica.

27 En italiano la traducción es de María Andrea Nicoletti. Aunque en el texto original indica: "Al publicar estas breves nociones sobre el idioma araucano, declaro que no he tenido intención de hacer una gramática, obra que por el momento me resultaría imposible, atendiendo a las múltiples ocupaciones de mi sagrado ministerio" (Milanesio, La Patagonia 6). Fue publicada en italiano-mapuzungun; contamos también con una versión al español manuscrita presuntamente realizada por el padre Zacarías Genghini, fechada el 1 de junio de 1907 en Bariloche (Río Negro).

28 La Exposición de Arte Sacro, de las Misiones Católicas y de las Obras de Caridad Cristiana se llevó adelante en Turín a partir del 20 de noviembre de 1898, conjuntamente con la Exposición General Italiana, que celebraba el quincuagésimo aniversario del Estatuto o Constitución. Las misiones salesianas de la Patagonia presentaron objetos culturales indígenas, ejemplares de la fauna nativa y publicaciones y manuscritos en los que se evidenciaba el método seguido para instruir y educar a los "salvajes". Agradecemos a Giovenale Dotta por la información que nos allegó acerca del tema. 


\section{FRONTERAS}

En la parte final aparece el texto en que nos centraremos: un catecismo bilingüe, que contiene 31 preguntas y sus respuestas, y las oraciones católicas más usuales (Señal de la cruz, Padre Nuestro, Ave María). Titulado Piccolo Catechismo en italiano, se presenta en la versión al mapuzungun como Puchi que zugu tañi quimael pu winca che, que podría versionarse como "unas pocas palabras para que conozcan los blancos", anotación que indexa los destinatarios de la publicación. Reelaboración abreviada - y en parte copia textual— del Manual de piedad ${ }^{29}$, toma también como modelo el Catecismo Limense y el texto de Febrés (que reproduce en 16 preguntas), en un texto que, por su brevedad, parece ser una síntesis de la síntesis que constituían los catecismos menores, como el "Resumen de las verdades de necesítate medii y de algunas necesitate praecepti para las personas incapaces de mayor instrucción", que adjunta Savino a su catecismo menor. El Piccolo Catechismo sigue la lógica del Credo explicando

[...] los misterios de la Unidad y la Trinidad, la creación del mundo, el hombre y su caída, la Encarnación, Pasión, Muerte y Resurrección de Jesucristo, el pecado en general, los mandamientos de Dios y de la Iglesia, el Paraíso para los buenos y el infierno para los malos. (BS 7 de 1884)

Se trata de un texto que integra lo estrictamente necesario para que se pueda ingresar a catequizar a los distintos grupos, y que - no olvidemos - fue publicado en italiano en medio de una obra cuyo objetivo era dar a conocer a los europeos, especialmente a los cooperadores, las "costumbres, la lengua, la industria y la religión" de los indígenas de la Patagonia: al reproducir estos breves interrogatorios y oraciones se muestra a los lectores, en un primer golpe de vista, un manejo importante de una lengua desconocida.

Un análisis de corte filológico del catecismo de Milanesio, en contraste con los demás, permite observar una cadena intertextual que integran los dos textos transandinos, además de las obras de Savino y Birot —algunas de cuyas proposiciones se reconocen en el suyo, con variantes de redacción-, ya sea por la reelaboración a la que se abocó cada uno de los autores, por la influen-

29 El Manual de piedad comprende: las oraciones más usuales (Padrenuestro, Ave María, Credo); Los Mandamientos de la Ley de Dios y de la Iglesia; Los Sacramentos; Ofrecimientos; Oración al Ángel de la Guarda; El Bendito; Las Oraciones de la Noche; Otras Oraciones Comunes; La Santa Misa; La Confesión; La Comunión; El Santo Rosario; El Catecismo de la Doctrina Cristiana; Cómo se bautiza en caso de necesidad; Obras de Misericordia; Bienaventuranzas; Novísimos del hombre; Buen Consejo, Días de guardar; Vigilias; Privilegios. 
cia de los indígenas con los que interactuaban o por las variantes diacrónicas favorecidas en la lengua. Los siguientes ejemplos permiten ilustrar estas afirmaciones. Febrés inquiere acerca de "¿Cuantos dioses hay?" mediante el pronombre interrogativo mufü (cuántos), en tanto que los otros autores usan chumten $\sim$ tunten, que es actualmente más usado a este lado de los Andes ${ }^{30}$; las otras divergencias se dan en el uso de $t a$, que marca la importancia pragmática del elemento siguiente, y en el caso de Savino, del morfema aspectual ke, el cual indica "acción habitual". Veamos:

- Febrés: 4. Mivuy cam ta Dios?/ Quiñe Dios mùten.

- Savino: 4. ¿Chumten ta Dios mlekey?/ Kiñe Dios mùten.

- Birot: 3. ¿Chumten Dios mley?/ Quiñe Dios mùten.

- Milanesio: 2. ¿Chumten Dios ta mley?/ Kiñe Dios mùten.

- Manual de piedad: 2. Tunten Dios ta m'lei?/ Quiñe Dios m’ten.

De modo similar, Milanesio reelabora del Manual de piedad y de Febrés la redención del pecado por parte de Jesús, pero la proposición parece haber sido tomada de Savino, ya que en este aparece la palabra montuam ("para salvar"), en vez de perdonangeam ("para ser perdonado"), como en Febrés; además del error de transcripción izuam (por zuam), repetido en el texto de Milanesio a partir del de Savino. La idea central del interrogante en Savino aparece en la pregunta, y en Milanesio y en el Manual de piedad, en la respuesta:

- Milanesio: 13. ¿Qué hizo por nosotros nuestro señor Jesucristo?/ Murió en la Cruz para liberarnos del pecado.

Chumi cam tain señor Jesu Cristo inchiñ taiñ izuam meu? / Lauyey wente cruz meu tain montuam werilcan meu.

- Manual de piedad: 13. ¿Qué hizo por nosotros Jesucristo?/ Murió en la Cruz por librarnos del pecado.

Chumi Jesu Cristo inchiñ taiñ duam? / Lauyei huente cruz meu tain montuam huerilcan meu.

30 Chumten también aparece en la proposición correspondiente en el ejemplo de catecismo de Falkner (169). 
- Savino 4, p. 43. ¿Por qué murió en la cruz nuestro señor Jesucristo?/ Por nosotros y por todos los hombres, para que nos libremos del infierno y para que consigamos el cielo.

Chumngelu cam lauyey taiñ Señor Jesucristo cruz mu?/ Inchiñ taiñ izuam, fill mapu che izuam cay, taiñ montuam cùthal mapu mu, taiñ pouam cay wenu mapu.

- Febrés: 10. ¿Por qué motivo murió nuestro Señor Jesu Cristo?/ Para que se nos perdonasen nuestros pecados y no vamos a dar al Infierno.

Chem ñi vla cam ta lay taiñ Señor Jesu Cristo? Taiñ perdonanmageam taiñ huerilcam, taiñ pounoal cay cùthal mapu meu.

En cuanto a las oraciones, la única versión idéntica es la de la señal de la cruz. Febrés constituye la fuente de las versiones del padrenuestro y el avemaría, y a partir de ella, en el Manual de piedad y en los textos de Milanesio y de Birot, se ingresan variantes motivadas por cuestiones gráficas, fonético-fonológicas, léxicas y sintácticas. En el cuadro comparativo del Padre Nuestro en mapuzungun presentado a continuación pueden contrastarse las versiones ${ }^{31}$.

\begin{tabular}{|c|c|c|c|}
\hline Febrés (1765) & Manual de piedad (1899) & Milanesio (1898) & Birot (1879) \\
\hline $\begin{array}{l}\text { Inchiñ taiñ Chao } \\
\text { huenu meu ta mleymi, } \\
\text { uvchigepe tami ghùy: } \\
\text { eymi tami reyno inchiñ meu } \\
\text { cùpape: } \\
\text { chumgechi tami piel } \\
\text { vemgequey ta huenu mapu } \\
\text { meu, } \\
\text { vemgechi cay vemgepe ta } \\
\text { tue mapu meu. } \\
\text { Chay elumoiñ taiñ vill antù } \\
\text { cofque: } \\
\text { perdonanmamoiñ taiñ } \\
\text { huerilcam, } \\
\text { chumgechi inchiñ } \\
\text { perdonaqueviiñ taiñ } \\
\text { huerilcaeteu; } \\
\text { lelmokiliñ taiñ } \\
\text { huerilcanoam: } \\
\text { hueluquemay vill huera que } \\
\text { dugu meu montulmoiñ. } \\
\text { Amen. }\end{array}$ & $\begin{array}{l}\text { Inchiñ taiñ Chao } \\
\text { huenu meu ta m'leimi, } \\
\text { saquignepe tami gui: } \\
\text { eymi tami reinu inchiñ meu } \\
\text { c'pape: } \\
\text { chumgnechi tami piel } \\
\text { femgnequei ta huenu mapu } \\
\text { meu, } \\
\text { femgnechi cai femgnepe ta } \\
\text { tue mapu meu. } \\
\text { Fachi ant'elumoiñ taiñ fill } \\
\text { ant' cofque; } \\
\text { frenemoaiñ taiñ huerilcan, } \\
\text { chumgnechi inchiñ } \\
\text { frenequefiem taiñ } \\
\text { huerilcaeteu; } \\
\text { elmoquilin taiñ } \\
\text { huerilcanoam: } \\
\text { hueluquemai fill hueda que } \\
\text { dugnu meu montulmoiñ. } \\
\text { Felepe. }\end{array}$ & $\begin{array}{l}\text { Inchiñ taiñ chao } \\
\text { wenu mapu ta mleymi, } \\
\text { ùfchi thucagepe tami ghùy } \\
\text { eymi tami reynu, inchiñ ta } \\
\text { cùpape, } \\
\text { chumgechi tami piel } \\
\text { femgequey ta wenu meu, } \\
\text { femgechi cay ta tue mapu } \\
\text { meu. } \\
\text { Inchiñ cofquen elumoiñ fil } \\
\text { antù meu, } \\
\text { perdonanmamoiñ taiñ } \\
\text { puerim, } \\
\text { chumgechi inchiñ } \\
\text { perdonaquefiñ taiñ } \\
\text { werilcaeteu; } \\
\text { entumokiliñ cay taiñ } \\
\text { werilcanoam } \\
\text { weluquemay fill weza que } \\
\text { zugu meu montulmoiñ, } \\
\text { felepe. }\end{array}$ & $\begin{array}{l}\text { Inchiñ taiñ Chao, } \\
\text { huenu meu ta mlelu, } \\
\text { saquinqueay tami ghùy; } \\
\text { inchiñ meu cùpape tami } \\
\text { gùnen; } \\
\text { chumuechi tami throquiel } \\
\text { vemuequy huenu meu, } \\
\text { vemuechi cay vemgepe ta } \\
\text { mapu meu. } \\
\text { Chay elumoiñ a Dios em! taiñ } \\
\text { vill antù cofque, } \\
\text { perdonalelmoiñ taiñ huerilcam } \\
\text { chumuechi inchiñ } \\
\text { perdonaqueviiñ taiñ } \\
\text { huerilcaqueeteu; } \\
\text { elelmoqueliñ cay taiñ } \\
\text { huerilcanoam } \\
\text { hueluquemay vill hueraque } \\
\text { dugu meu montulmoiñ. } \\
\text { Velepe. }\end{array}$ \\
\hline
\end{tabular}

31 Un análisis similar puede hacerse de las distintas versiones del avemaría. 
De la grafía se desprende el uso sistemático de los fonos $\mathrm{f} / \mathrm{z}$ en las oraciones de Milanesio y el Manual de piedad, en tanto que en Febrés y Birot se usan prevalentemente $\mathrm{v} / \mathrm{d}$; esta pauta homogénea en el habla de los mapuche con los que interactuó Milanesio nos permite hipotetizar que no se trataría de hablantes de las variedades ubicadas geográficamente al norte (pikumche y ranquel), ya que en estas se presentan típicamente los fonos registrados por Birot. En cuanto a la variación léxica, en algunos casos no modifica el significado referencial: tue mapu/ mapu ("tierra"), reyno/reynu/günen ("reino"), puerim ( $p$ w werim) ("pecados") /huerilcam ("pecado"), chay/ fachantü ("hoy"); en tanto que en otros permite expresar matices semánticos diversos: uvchigepe ("sea reverenciado") /ùfchithucagepe ("sea respetado con reverencia") /saquinqueay ("sea honrado, apreciado"), piel ("lo que dice") /throquiel ("mandamiento, lo que manda"), perdonanmamoiñ/ perdonalelmoiñ ("perdónennos", refiriéndose el morfema benefactivo -ñma-, en el primer caso, a una acción en contra del dativo receptor los hombres, y -lel-, en el segundo, a favor del mismo). Otras variantes se manifiestan en el cambio de orden de los elementos oracionales: dado que en mapuzungun el orden sintáctico marcado destaca información pragmática, las variaciones estructurales implican ese resalte de un elemento sobre otro, como puede verse en: Inchiñ cofquen elumoiñ fil antù meu ("A nosotros pan danos cada día") / Chay elumoiñ a Dios em! taiñ vill antù cofque ("Hoy danos, ¡oh, Padre!, nuestro pan cotidiano").

Los distintos textos de Milanesio que hemos analizado, si bien reiteran temáticas, no son idénticos entre sí. El repaso del credo del Bollettino salesiano no reproduce las mismas preguntas que el Piccolo catecismo; el interrogatorio previo al bautismo de Raccolta di vedute [...] difiere del publicado en los Bollettini (BS 1 de 1912). Y aunque Milanesio copie de sus predecesores, como efectivamente lo hace, reelabora y adapta la doctrina de acuerdo con las circunstancias de la misión.

Una última cuestión que constituye una hipótesis para seguir indagando es la probable existencia de otra fuente que habría modificado previamente los catecismos jesuitas, y sobre la que hubieran intervenido tanto el Manual de piedad como los catecismos lazaristas y sus sucesores. Esto se desprende de ciertas irregularidades que hacen divergir los textos del siglo XIX de los anteriores; pero por el momento, ante la falta de datos disponibles, es una temática que solo podemos señalar ${ }^{32}$.

32 Para poder completar la cadena intertextual a la que hacemos referencia, nos hemos encontrado con importantes dificultades en el hallazgo del material en nuestro país. Las obras de Milanesio fueron encontradas en el Archivo Salesiano de Roma y en el Instituto Íbero- 


\section{FRONTERAS}

de la fistoria

Vol.13-1 / 2008

\section{Conclusiones}

Para finalizar, resaltaremos algunas ideas desarrolladas en nuestra exposición. En la práctica misionera católica a partir del siglo XVI en territorio mapuche se produjeron diversos instrumentos de evangelización, entre los que pueden establecerse relaciones intertextuales. A la par, se detectaron en las mismas variantes lingüísticas relacionadas con los dialectos de los distintos grupos mapuche y con los cambios que tuvo la lengua a lo largo del tiempo. De esos catecismos, más que de lo recogido por la interacción con los indígenas catequizados, abrevó el salesiano Milanesio en sus propias producciones. Contando con un moderado conocimiento del mapuzungun, Milanesio optó por adaptar el catecismo menor de Febrès y copiar, casi textualmente, el Manual de piedad poniendo especial atención a los catecismos de quienes fueron sus antecesores inmediatos: los lazaristas. De este modo, su prédica por medio de la lengua vernácula le posibilitó un ingreso inmediato a los grupos indígenas, sometidos y diezmados, para efectuar su tarea evangelizadora, así como un reconocimiento especial dentro de su congregación.

Para Milanesio, el uso del mapuzungun fue una herramienta de evangelización y, fundamentalmente, de penetración, con la que iniciaba su misión, tal como lo prueban distintos relatos en los Bollettini Salesiani y en Raccolta di vedute. Las publicaciones que efectuó tenían como objetivo dar a conocer el territorio misionero y la labor que se realizaba por los indígenas ("Carta de Milanesio"; Milanesio, "Apuntes"). Para sus lectores, alejados de este territorio y de la cultura originaria, los textos en mapuzungun causaban una impresión inmediata sobre una cultura a la que la mirada etnocéntrica posicionaba en un plano inferior, $y$, a su vez, causaba admiración el manejo de la lengua en un misionero que estaba cumpliendo una tarea "heroica", como la de evangelizar "infieles".Para sus superiores, Milanesio cumplía con las sugerencias del Concilio Plenario de 1899 y con las indicaciones de Don Bosco: la adaptación a la cultura del lugar y el manejo de la lengua donde se propagaba la fe (Ceria 576-578).

Americano de Berlín; los catecismos de la orden capuchina y el confesionario de Calzada, en la biblioteca de la Universidad de Eichstätt, y el Manual de piedad, en la Biblioteca Nacional de Chile. Agradecemos a los colegas: Dra. Roswitha Kramer, Padre Meinrado Hux, Lic. Walter Burriguini, Dr. Rafael Sagrado, Francesco Motto y Cintia Angelucci. Si bien tenemos la referencia de que el catecismo de Serviliano Orbanel, OFM, "Doctrina Cristiana, catecismo, forma de administrar los sacramentos con 22 pláticas en araucano", de 1778, se encuentra en la Biblioteca Americana del Museo Mitre (Buenos Aires), no hemos podido acceder a este material, pues el museo se encuentra en reparación. 
Si bien los textos catequísticos en mapuzungun provistos por Milanesio son breves y asistemáticos, y sus estudios sobre etimología y orígenes de la lengua reelaboran distintas fuentes con resultados muy desparejos, e, incluso, con errores serios, es de destacar que Milanesio fue el único de los misioneros salesianos de la Patagonia Norte que mostró un interés especial en el conocimiento y la difusión de la lengua. Por ello, la exposición de su práctica lingüística, sobre todo de los textos que remiten a la evangelización oral, aun con sus limitaciones, nos permite atisbar aspectos poco conocidos de la relación entre indígenas y misioneros en la época inmediatamente posterior al awkan o conquista militar del territorio indígena.

\section{Bibliografía}

\section{Fuentes primarias}

Augusta, Fray Felix José de. Lecturas Araucanas. Valdivia: Imprenta de la Prefectura Apostólica, 1910.

Barbará, Federico. Manual de la lengua pampa. Buenos Aires: Emecé, 2000.

Birot, José. Pequeño catecismo castellano-indio. Para enseñar la doctrina cristiana a los indios que están en casa de particulares. Buenos Aires: Imprenta de la América del Sur, 1879.

Bollettini Salesiani, Roma (BS), 7 de 1881, 1883, 1884; 11 de 1884, 1885; 8, 12 de $1886 ; 1,2,3,5,10$ de $1887 ; 6,11,12$ de $1889 ; 7,10$ de 1890 ; 2,3,7,10 de 1891; 9 de 1892; 1,2,4,11 de 1893; 2,7 de 1895; 9 de $1896 ; 9$ de $1899 ; 1,3,4,5,7,8,9,10$ de $1903 ; 8$ de $1904 ; 1,7$ de 1909; 1 de 1912; 9 de 1913; 11 de 1916; 2 de 1923.

Ceria, Eugenio. Epistolario di San Giovanni Bosco. Vol. 3. Torino: SEI, 1958.

Febrès, Andrés. Gramática Araucana o sea de la Lengua General de los Indios de Chile. Lima: s.e., 1765.

Havestadt, Bernardo. Chilidugu sive Tractatus Linguae Chilensis. Westfalia, Alemania: s.e., 1777.

Manual de piedad en castellano y en mapuche (araucano) para texto de lectura de los indígenas de Chile. Edición revisada por el Dr. Rodolfo 


\section{FRONTERAS}

de la fistoria

Lenz y costeada por el Supremo Gobierno. Santiago de Chile: Imprenta de San José, 1899.

Milanesio, Domingo. La Patagonia, lingua, industria, costumi e religione dei Patagoni. Buenos Aires: Escuela Profesional de Tipógrafos del Colegio Pío IX de Artes y Oficios, 1898.

-. Raccolta di vedute delle missioni salesiane. Torino: Oratorio San Francesco de Sales, 1904.

- Etimología araucana. Idiomas comparados de la Patagonia. Lecturas y frasario araucano. Buenos Aires: Talleres Gráficos del Estado Mayor del Ejército, 1915.

-. Estudios y apuntes sobre las lenguas en general y su origen divino. Particularidades sobre los idiomas de la Patagonia. Buenos Aires: Imprenta San Martín, 1917.

Obispos de América Latina. Concilio Plenario de la América Latina, Roma: s.e., 1899. Biblioteca electrónica cristiana. Obtenido de la red mundial el 9 de junio de 2004, 9:00 horas. <http://multimedios. org/docs/d000021/>.

Perón, Juan Domingo. Toponimia Patagónica de Etimología Araucana. Buenos Aires: Dirección General de Cultura - Ministerio de Educación, 1950.

Savino, Pablo Emilio. Pequeño Manual del Misionero para evangelizar a los indios fronterizos. [1876]. Buenos Aires: Imprenta de Pablo Coni, 1900.

Valdivia, Luis de. Arte y gramática general de la lengua que corre en todo el Reyno de Chile : con un vocabulario, y confessionario. [1606]. Lima: s.e., 1684.

\section{Documentos inéditos}

"Apuntes de una breve conferencia sobre los indios de la Patagonia en la Capilla de María Auxiliadora de San Carlos" (Buenos Aires). Archivo Central Salesiano (ASC), Buenos Aires, Caja Milanesio. 
"Carta de Domingo Milanesio a Don Bosco" (Patagones, 1 de septiembre de 1886). Archivio Salesiano Centrale (ASC), Roma, B 284. (Original en italiano).

"Carta de Domingo Milanesio a Juan Bosco" (Carmen de Patagones, 26 de octubre de 1886). Archivio Salesiano Centrale (ASC), Roma, B 284. (Original en italiano).

"Carta de Milanesio a Paolo Albera" (Bernal, 30 de mayo de 1917). Archivo histórico de las Misiones Salesianas de la Patagonia Norte (AHMSP) (Bahía Blanca), Correspondencia Milanesio.

"Legado Juan Benigar". Archivo particular de Juan Benigar. Plaza Huincul. Provincia del Neuquén, Argentina.

\section{Fuentes secundarias}

Catálogo Ecos históricos de la Patagonia. Aborígenes y misioneros, siglo $X I X$. Buenos Aires: Pontificia Universidad Católica Argentina, 2004.

Durán, Juan Guillermo. El catecismo del III Concilio Provincial de Lima y sus complementos pastorales (1584-1585). Buenos Aires: El derecho, 1982.

—. "Catecismos pampas (1870-1885). Circunstancias históricas y alcances pastorales". Revista Teología 1. 69 (1997): 5-69.

-. En los Toldos de Catriel y Railef. La obra misionera del padre José María Salvaire en Azul y Bragado, 1874-1876. Buenos Aires: Facultad de Teología de la Universidad Católica Argentina, 2002.

Falkner, Thomas. Descripción de la Patagonia y de las partes contiguas de la América del Sur. Buenos Aires: Hachette, 1957.

Foerster, Rolf. Introducción a la religiosidad mapuche. Santiago de Chile: Universitaria, 1993.

Garófoli, José. Datos biográficos y excursiones apostólicas del Rvdo. D. Domingo Milanesio, misionero salesiano. Turín, Italia: San Benigno Canavese, 1928. 


\section{FRONTERAS}

de la fistoria

Gaófuli, José. Breve reseña de apuntes más relevantes de actuación del Padre Domingo Milanesio en la Patagonia. Buenos Aires: Colegio Pío IX, 1915.

Hux, Meinrado. Coliqueo, el indio amigo de Los Toldos. Los Toldos, Argentina: Ediciones del autor, 1999.

Malvestitti, Marisa y María Andrea Nicoletti. "Padre Patiru. Usos y funciones del mapuzungun en la práctica misionera del salesiano Domenico Milanesio". Ponencia. II Congreso Internacional de LaS LenguaS, Buenos Aires, 19 al 21 de julio de 2007.

- "Evangelizar en mapuzungun: la práctica lingüística del salesiano Domenico Milanesio en el proceso de expansión territorial winka (1880-1914)". Ponencia. XI Jornadas Interescuelas de Departamentos de Historia, Tucumán, 19 al 22 de septiembre de 2007.

Nicoletti, María Andrea. "Una puesta en escena de la evangelización salesiana en la Patagonia: entre 'infieles' y 'conversos'. Revista Tefros. 3. 1 (2005).

-. "Bases y principios para la evangelización salesiana en Patagonia: el primer reglamento misionero de Domenico Milanesio (1912)". Revista Atek na [En la tierra] 1 (2003): 115-136.

Paesa, Pascual. Patiru Domingo, la cruz en el ocaso mapuche. Rosario: Instituto Salesiano de Artes Gráficas, 1964.

Pérez Zavala, Graciana. "Oralidad y escritura: los tratados de paz entre el estado argentino y las tribus ranqueles". Revista Tefros 3.1 (2005).

Quijada, Mónica. "El paradigma de la homogeneidad". Homogeneidad y Nación con un estudio de caso: Argentina, siglos XIX y XX. Eds. Mónica Quijada, Carmen Bernard y Arn Schneider. Madrid: Consejo Superior de Investigaciones Científicas, 2000. 15-56.

Fecha de recepción: 10 de diciembre de 2007.

Fecha de aprobación: 15 de mayo de 2008. 